\title{
EL ACUERDO DE PARÍS DE DICIEMBRE DE 2015: LA SUSTITUCIÓN DEL MULTILATERALISMO POR LA MULTIPOLARIDAD EN LA COOPERACIÓN CLIMÁTICA INTERNACIONAL
}

\author{
Sergio Salinas AlCEgA*
}

SUMARIO: 1 . NOTA INTRODUCTORIA.-2. EL ESQUEMA DE LA DIPLOMACIA CLIMÁTICA PRE-PARÍS.-2.1. Una gestión (formalmente) multilateral.-2.2. La multilateralidad se transforma en multipolaridad en el desarrollo práctico del modelo.-3. EL ACUERDO DE PARÍS: MOTIVOS PARA LA ESPERANZA EN EL PLANO PROCEDIMENTAL.-3.1. El cambio de rumbo en cuanto al proceso negociador-3.2. Por fin un texto jurídico-internacional en materia de cambio climático tras dos décadas.-4. EL ACUERDO DE PARÍS: UN CAMBIO DE RUMBO ¿DECEPCIONANTE? EN LO SUSTANTIVO.-4.1. El establecimiento de un modelo de gestión basado en la flexibilidad.-4.2. ¿Flexibilidad o ambigüedad del nuevo esquema de atribución de obligaciones en materia de mitigación?-4.3. El papel del voluntarismo en la contribución al esfuerzo de mitigación.--5. CONCLUSIONES.

\section{NOTA INTRODUCTORIA}

La condición del clima como bien compartido por todos los Estados y su carácter insustituible permiten afirmar que el régimen de lucha contra el calentamiento global reproduce fielmente el dilema de la tragedia de los comu$n e{ }^{1}$. Esa afirmación se fundamenta en que la naturaleza global del problema exige un modelo de gestión del mismo igualmente global, que encuentra su materialización en la estructura jurídica creada por la Convención Marco de las Naciones Unidas contra el Cambio Climático (CMNUCC) ${ }^{2}$. Sin embargo,

* Este trabajo se enmarca en el Proyecto de Investigación DER2015-66045-P financiado por el Ministerio de Economía y Competitividad y en las actividades del Instituto Universitario de Ciencias Ambientales de la Universidad de Zaragoza. Igualmente debe entenderse comprendido dentro de las actividades a que se dedica el Grupo Consolidado de Investigación AGUDEMA, financiado por el Gobierno de Aragón y el Fondo Europeo de Desarrollo Regional. Profesor Titular de Derecho internacional público en la Universidad de Zaragoza (ssalinas@unizar.es).

1 Hardin, G., «The Tragedy of the Commons», Science, vol. 162, 13 de diciembre de 1968, Issue 3859, pp. 1243-1248.

2 Convención Marco de las Naciones Unidas sobre el cambio climático, hecha en Nueva York el 9 de mayo de 1992, BOE núm. 27, de 1 de febrero de 1994. 
la eficacia de ese modelo resulta severamente dañada por comportamientos individuales que obstaculizan la satisfacción del interés general de reducir un fenómeno con graves consecuencias actuales y futuras. Ello a pesar de que, conforme a los datos que ofrece la ciencia, los free riders resultarán también perjudicados por los efectos negativos del calentamiento global.

De hecho, el régimen climático internacional es uno de los ámbitos en los que con más claridad se plantea el obstáculo que para la articulación de modelos de gestión de bienes comunes representa el papel que la soberanía estatal sigue jugando en el Derecho internacional actual. Papel que se traduce en la capacidad de cada Estado de decidir de manera individual sustraerse del imprescindible esfuerzo colectivo, limitando la efectividad del esquema de cooperación global.

El Acuerdo adoptado en la 21. ${ }^{a}$ Conferencia de las Partes (COP), en diciembre de 2015, representa, sin duda, un cambio de rumbo en el modelo de cooperación climática internacional ${ }^{3}$. Nuestro propósito es analizar los cambios operados por ese texto desde la perspectiva del reforzamiento o debilitamiento de su naturaleza multilateral. Con ese fin en primer lugar se estudiará la adecuación del modelo anterior a París a la gestión de un bien público global, no circunscribiéndonos a las claves formales del mismo sino prestando atención, muy especialmente, a las limitaciones resultantes de su puesta en práctica (2). Ese análisis servirá de base para valorar los cambios introducidos por el Acuerdo de París ${ }^{4}$ desde la perspectiva apuntada. Para ello se estudiarán las líneas principales del nuevo esquema que surge de la capital francesa, poniendo el acento en aquellos aspectos que implican un cambio respecto del modelo anterior. Ese análisis comenzará por el plano

\footnotetext{
3 Cuya utilidad era advertida tanto por la doctrina como por el Grupo Intergubernamental de Expertos sobre el Cambio Climático (IPCC, en sus siglas en inglés) en los análisis comparativos realizados entre ambos modelos, el consagrado en el Acuerdo de París y el anteriormente vigente. En ese sentido, a nivel doctrinal pueden mencionarse a modo de ejemplo: LEAL-ARCAS, R., «Top-Down versus Bottom-Up Approaches for Climate Change Negotiations: An Analysis», The IUP Journal of Governance and Public Policy, vol. 6, diciembre de 2011, núm. 4, pp. 7-52; PIckering, J., «Top-Down Proposals for Sharing the Global Climate Policy Effort Fairly: Lost in Translation in a Bottom-Up World?», en Breakey, H., Popovsky, V. y Maguire, R. (eds.), Ethical Values and the Integrity of the Climate Change Regime, Nueva York, Routledge, 2016, pp. 8-104. Por su parte, el análisis comparativo en el seno del IPCC se incluye en una fase relativamente temprana pudiendo citar como ejemplo el desarrollo que al respecto se hace en el marco del III Informe de Evaluación. METz, B., et al. (eds.), Climate Change 2001: Mitigation. Contribution of the WGIII to the Third Assessment Report of the Intergovernmental Panel on Climate Change, Cambridge, Cambridge University Press, 2001, pp. 489-490. En ese mismo sentido, la necesidad del cambio de rumbo es señalada por el Papa Francisco quien, partiendo de la inexistencia de avances significativos con el modelo anterior, que primaba los intereses particulares sobre el bien público global, fijaba como objetivo del nuevo modelo alcanzar un equilibrio entre soberanía y gestión adecuada, e identificaba como líneas de acción la adopción de marcos regulatorios globales que impongan obligaciones y de instituciones internacionales más fuertes y eficazmente organizadas, con autoridades designadas equitativamente por acuerdo entre los gobiernos y dotadas de poder para sancionar. Véase Carta Encíclica Laudatio Si' del Santo Padre Francisco sobre el cuidado de la casa común, especialmente pp. 127-135, disponible en http://w2.vatican.va/content/francesco/es/encyclicals/documents/papa-francesco_20150524_enciclica-laudato-si.html (consultada el 22 de noviembre de 2017).

4 Acuerdo de París, hecho en París el 12 de diciembre de 2015, BOE núm. 28, de 2 de febrero de 2017.
} 
procedimental, lo que incluirá el resultado final del proceso negociador, aunque desde esa perspectiva meramente formal (3). Después entraremos en un análisis sustantivo del citado Acuerdo, valorando hasta qué punto los cambios introducidos permiten esperar que el nuevo esquema de cooperación resulte más efectivo en la reacción contra el calentamiento global (4). El estudio terminará con unas conclusiones que subrayarán los principales aportes y las deficiencias más destacadas de la nueva diplomacia climática (5).

No obstante, el análisis de las distintas dimensiones del régimen jurídicointernacional contra el cambio climático se convierte en algo utópico por las lógicas y razonables exigencias de extensión que debe tener este estudio. Por ese motivo el giro de la diplomacia climática se estudiará centrando el enfoque en la dimensión principal del esfuerzo, la relativa a la mitigación, cuyo carácter principal resulta tanto de su condición de vector primero de reacción contra el calentamiento global como de su influencia sobre la acción en las otras dimensiones - adaptación, financiación, transferencia de tecnología y formación de capacidades- en las que la intensidad en el esfuerzo es inversamente proporcional a los logros obtenidos en el plano de la reducción de emisiones de gases de efecto invernadero (GEI). Cuanto mayores sean estos, menor será la actuación a desarrollar en los demás planos, en especial en el de la adaptación, dado que la menor magnitud del calentamiento global reducirá también el esfuerzo necesario para adaptarse a sus impactos.

\section{EL ESQUEMA DE LA DIPLOMACIA CLIMÁTICA PRE-PARÍS}

Este apartado aborda el estudio del modelo de gestión del clima establecido por la CMNUCC, desarrollada por el Protocolo de Kyoto ${ }^{5}$, prestando atención tanto a lo recogido en los textos como a su aplicación en la práctica.

\subsection{Una gestión (formalmente) multilateral}

Nuestro análisis parte de la consideración de que los textos citados establecen un sistema de diplomacia climática multilateral y con un alcance global, al menos en una perspectiva formal y especialmente por lo que se refiere al primero de ellos, que en principio se adaptaría a las exigencias de la gestión de un bien público global. Esta afirmación se fundamenta en la participación universal en el contexto de la $\mathrm{CMNUCC}^{6}$, así como en la identificación de un órgano plenario, la COP, como el órgano supremo del citado modelo ${ }^{7}$.

\footnotetext{
5 Protocolo de Kyoto al Convenio Marco de las Naciones Unidas sobre el Cambio Climático. Hecho en Kyoto el 11 de diciembre de 1997, BOE núm. 33, de 8 de febrero de 2005.

${ }^{6}$ La CMNUCC, en vigor desde el 21 de marzo de 1994, cuenta con 197 Partes. Véase Status of Ratification of the Convention, disponible en http://unfccc.int/essential_background/convention/status_ of_ratification/items/2631.php (consultada el 22 de noviembre de 2017).

7 Conforme al art. 7.2 de la CMNUCC, lo que se concreta en una serie de competencias recogidas tanto en esa como en otras disposiciones de dicho texto, destacando el art. 17, conforme al cual la COP es la encargada de adoptar Protocolos que desarrollen la Convención.
} 
Sin embargo, ese juicio favorable a la idoneidad del modelo para la gestión de un bien público global se ve aminorado si se atiende al procedimiento decisorio seguido por la COP, cuyo ideal para el objetivo propuesto sería el de un esquema basado en la decisión por mayoría que permitiese una participación de todos los Estados, excluyendo que uno, o varios de ellos que no alcanzasen un umbral mínimo, pudiesen condicionar el funcionamiento del modelo de gestión. La dificultad para el establecimiento de un procedimiento decisorio de esas características resulta en este caso no solo del elevado número de actores concernidos sino también de la complejidad de los intereses en juego en una cuestión con implicaciones de carácter global. La cuestión es que el cumplimiento de la obligación, establecida en el art. 7.3 de la CMNUCC, de que la $\mathrm{COP}$ aprobase su propio reglamento en su primer periodo de sesiones, incluyendo los procedimientos para la adopción de decisiones sobre asuntos a los que no se apliquen los establecidos en la propia CMNUCC, encontró precisamente en esta cuestión un serio obstáculo. El resultado fue la decisión, adoptada en su segundo periodo de sesiones, de aplicar el proyecto de Reglamento presentado en la primera sesión sin el art. 42, dedicado precisamente al procedimiento de votación ${ }^{8}$. La única mención expresa a procedimientos de votación en la COP es la que se recoge en el art. 15.3 de la CMNUCC en relación con la adopción de enmiendas a la misma, previéndose el consenso como procedimiento normal y la aprobación por una mayoría cualificada, de tres cuartos de las Partes presentes y votantes en la reunión, como último recurso. El resultado es la configuración de ese órgano, tal como afirma Jutta Brunnée, como el foro en el que las Partes adoptan el Protocolo o enmienda, pero cuyas decisiones no alteran los derechos y obligaciones de cada una de ellas $^{9}$. Así los Estados no pueden vetar las enmiendas adoptadas por la COP, pero tampoco pueden ser obligados por estas ya que su entrada en vigor se

\footnotetext{
8 Véase Proyecto de reglamento de la Conferencia de las Partes y sus órganos subsidiarios (FCCC/ CP/1996/2, de 22 de mayo de 1996, párr. 2). Respecto de lo decidido en el primer periodo de sesiones, véase FCCC/CP/1995/7, de 24 de mayo de 1995, párr. 10. Y en cuanto al Proyecto de Reglamento, véase A/AC.237/L.22/Rev.2.

${ }^{9}$ La autora, si bien califica la COP como focal point de las actividades legislativas en materia de cambio climático, planteando incluso su evolución hacia una legislatura global en la materia, recuerda la estructura del Derecho de los tratados basada en el consentimiento, afirmando que en cuanto órgano plenario en el que se adoptan las decisiones de aplicación y desarrollo de la CMNUCC, incluidas las que implican asunción de obligaciones por las Partes, representa un híbrido entre una conferencia diplomática sobre una cuestión específica y un órgano permanente de una Organización internacional. En ese sentido el reforzamiento del papel legislativo de la COP conllevaría en opinión de Jutta Brunnée tanto ventajas como inconvenientes, puesto que si bien superaría los límites de la exigencia del consentimiento en Derecho internacional expondría la gobernanza climática a desafíos desde la perspectiva de la legitimidad, además del factor de la ambigüedad existente respecto de la naturaleza jurídica de las decisiones de ese órgano. Brunnée, J., "COPing with Consent: Law-Making Under Multilateral Environmental Agreements», Leiden Journal of International Law, vol. 15, 2002, pp. 1-52, esp. pp. 3 y 16-18. Sobre esta cuestión resulta relevante la afirmación de Enrique Martínez en el sentido de que si bien la COP del clima es un órgano supremo y asambleario con capacidad decisoria, el consenso supone, como ya ocurrió en el segundo periodo de sesiones a la hora de aprobar la Declaración Ministerial de Ginebra, que un solo país puede impedir la adopción de decisiones presentando alguna objeción formal. MARTínez PÉREZ, E. J., "La naturaleza jurídica de las decisiones adoptadas por la Conferencia de las Partes en el Protocolo de Kyoto», Revista Electrónica de Estudios Internacionales, vol. 13, 2007, pp. 1-22, esp. p. 7.
} 
limita, conforme al art. 15.4 y 5 de la CMNUCC, a aquellas Partes que las hayan ratificado.

Además, la adecuación del esquema de cooperación climática a la globalidad del problema se ve menoscabada en mayor medida por el Protocolo de Kyoto, cuyo nivel de participación si bien no está muy alejado en términos de cifras del de la CMNUCC presenta sin embargo ausencias significativas, como la de los Estados Unidos, a la que se aludirá más tarde ${ }^{10}$. Esta circunstancia cobra especial relevancia por la condición del citado Protocolo como el texto que concreta los compromisos de reducción de emisiones de los Estados Parte del sistema.

El resultado es que desde la perspectiva de la aportación efectiva al esfuerzo colectivo la globalidad del esquema de gestión climática establecido en la CMNUCC y el Protocolo de Kyoto resulta socavada por dos factores: el primero inherente al propio sistema, dado que, conforme a la CMNUCC, especialmente su art. 4.2, tan solo se atribuyen obligaciones de reducción de emisiones de GEI a los países del Anexo I, esencialmente los países desarrollados. Eso implica a sensu contrario la exclusión del esfuerzo de mitigación de todas las Partes no incluidas en el citado Anexo, identificadas como países en desarrollo. La merma del carácter global que resulta de ese sistema de emisiones exentas se agrava desde la perspectiva de la eficacia del mismo como consecuencia de la rápida modificación del mapa de emisiones. Nos referimos en concreto a que algunos de los considerados como países en desarrollo se han instalado entre los emisores principales de GEI. Ese es el caso de los países emergentes, y muy en especial de China, que en un lapso relativamente reducido de tiempo se ha convertido en el principal emisor ${ }^{11}$.

Ese escenario, además de poner en cuestión la concreción dada a uno de los principios vertebradores del esfuerzo colectivo de lucha contra el cambio climático, el de las Responsabilidades Comunes pero Diferenciadas, basado exclusivamente en el criterio de la responsabilidad histórica ${ }^{12}$, suponía condenar de forma irremediable al sistema al fracaso, puesto que los beneficios resultantes del cumplimiento de sus compromisos por los países del Anexo I son compensados con creces por el incremento de las emisiones de GEI de los excluidos de la obligación de reducción de las mismas.

10 El Protocolo de Kyoto cuenta con 192 Partes. Véase Status of Ratification of the Kyoto Protocol, disponible en http://unfccc.int/kyoto_protocol/status_of_ratification/items/2613.php (consultada el 22 de noviembre de 2017).

11 El caso del gigante asiático, que en 2014 doblaba ya en cuanto al volumen de emisiones, con un 30 por 100 del total, al segundo principal emisor, los Estados Unidos, cuya contribución representaba el 14 por 100, es el más relevante pero no el único, puesto que la condición de emisores principales es aplicable a otros países en desarrollo, según la CMNUCC, como India, que con un 7 por 100 de las emisiones totales ocuparía la tercera posición, y en menor medida Brasil, Suráfrica, México o Indonesia situados respectivamente en los lugares $11 .^{\circ}$ a $14 .^{\circ}$ Véase al respecto http://cdiac.ornl.gov/trends/ emis/top2014.tot.

12 Aproximación descrita como North first approach en Bотне, M., "The United Nations Framework Convention on Climate Change - an Unprecedented Multilevel Regulatory Challenge», Zeitschrift für ausländisches öffentliches Recht und Völkerrecht, vol. 63, 2003, pp. 239-254, esp. p. 240. 
El segundo factor limitante de la globalidad del sistema es consecuencia del papel ya señalado de la soberanía del Estado en la gestión de un bien público global, traducido en la libre aceptación de los compromisos recogidos en un tratado internacional por cada Estado, conforme al art. 11 de la Convención de Viena sobre el Derecho de los Tratados de 23 de mayo de $1969^{13}$. Así, Estados Unidos, en aquel momento el mayor emisor de GEI, firmaba el Protocolo el 12 de noviembre de 1998, pero no procedía a su ratificación, viéndose de esa manera exonerado de obligaciones en materia de mitigación.

La situación empeoraría con ocasión de la adopción de la Enmienda de Doh $a^{14}$, adoptada el 8 de diciembre de 2012, en la $18 .{ }^{a}$ COP, y que incluía compromisos de mitigación para un segundo periodo de cumplimiento del Protocolo de Kyoto entre 2013 y 2020. Con este texto se pretendía resolver el problema del vacío jurídico generado por el resultado de la $15 .{ }^{a} \mathrm{COP}$, de diciembre de 2009. El carácter político del Acuerdo entonces adoptado, al que se aludirá más tarde, traía como consecuencia que, ante la imposibilidad de alcanzar un consenso respecto de un texto de naturaleza jurídica, no se asegurase la continuidad de los compromisos de mitigación tras el fin de la vigencia de Kyoto. A eso se añade que el límite ya señalado que el Protocolo de Kyoto representa respecto del carácter todavía multilateral, pero ya no global, del modelo de gestión del clima en lo que respecta a la mitigación se agranda tras la citada Enmienda, que no era ratificada por Estados como Canadá, Japón o Rusia. La consecuencia era que el régimen climático se alejaba mucho más del carácter global, pudiendo identificarse como un modelo prácticamente regional, centrado en los Estados miembros de la Unión Europea, junto a otros países europeos como Noruega o Suiza, y algunos, pocos, de otras partes del mundo, como Australia. La magnitud de esa limitación se percibe en el plano cuantitativo puesto que los compromisos resultantes de ese texto conciernen apenas al 15 por 100 de las emisiones totales de GEI. Y a ello se añade que la Enmienda no ha llegado a entrar en vigor al no reunir el número de ratificaciones necesarias ${ }^{15}$.

\subsection{La multilateralidad se transforma en multipolaridad en el desarrollo práctico del modelo}

El análisis de la CMNUCC y del Protocolo de Kyoto nos ha mostrado que el juicio inicial acerca de la idoneidad del modelo climático desde la perspec-

13 Convenio de Viena sobre el Derecho de los Tratados, adoptado en Viena el 23 de mayo de 1969, BOE núm. 142, de 13 de junio de 1980.

14 Decisión 1/CMP.8. Enmienda al Protocolo de Kyoto de conformidad con su artículo 3, párrafo 9 (Enmienda de Doha) (FCCC/KP/CMP/2012/13/Add.1, 28 de febrero de 2013, p. 2).

15 La entrada en vigor de la Enmienda de Doha se somete a la ratificación de tres cuartos de las Partes del Protocolo de Kyoto, conforme a sus arts. 20 y 21, lo que supone 144 Partes de este, siendo 94 las que han presentado su aceptación. Sobre el estado de ratificación de la citada Enmienda, véase United Nations Treaty Collection, disponible en https://treaties.un.org/Pages/ViewDetails. aspx?src=TREATY\&mtdsg_no=XXVII-7-c\&chapter=27\&clang=_en (consultada el 22 de noviembre de 2017). 
tiva de la gestión de un bien público global se ve matizado por algunos factores que reducen de forma relevante su alcance, alejándose de la globalidad. No obstante, esos límites se incrementan por el hecho de que el mencionado mecanismo multilateral no ha funcionado como tal en el sentido de una corresponsabilidad en términos igualitarios de todas las partes y, lo que es quizás más relevante, en cuanto al reconocimiento de un nivel de participación similar de todas ellas. Si bien los textos parecían diseñar un sistema que se canalizaba a través de esas vías, su desarrollo práctico parece salirse de las mismas. El mejor ejemplo de esta afirmación es lo ocurrido con ocasión de la ya mencionada COP de Copenhague de 2009. Este había sido el momento fijado para alcanzar un Acuerdo que permitiese prorrogar el régimen de obligaciones de reducción de emisiones de GEI fijado en el Protocolo de Kyoto, que, aunque defectuoso, era evidentemente menos malo que una ausencia absoluta de compromisos en ese sentido, y que concluía su vigencia el 31 de diciembre de 2012, conforme al art. 3.1 de dicho texto.

El resultado alcanzado en la capital danesa era insuficiente tanto en el fondo como en la forma. La insuficiencia formal resulta de que lo único que se lograba en esa ocasión era un gentlemen's agreement, por más que la denominación del mismo como "Acuerdo» pudiera inducir a pensar otra cosa. La insuficiencia sustantiva se debía a que el citado texto ni siquiera era el resultado del funcionamiento normal del mecanismo previsto en la CMNUCC. Es decir, que el Acuerdo no era fruto del debate multilateral en el marco de la COP, sino que su contenido era negociado fuera de la sala y únicamente por un reducido número de Estados, siendo presentado más tarde al órgano jurídicamente competente que veía reducido su papel al mero endoso del texto puesto sobre la mesa. El multilateralismo formal parecía sustituirse por una suerte de multipolaridad, muy cercana a la concepción china de las relaciones internacionales ${ }^{16}$, fundamentada en una distribución equilibrada de poder entre varios polos que evite opciones unilaterales dominantes, en la que la voluntad individual, especialmente de los actores principales, cobra mucha mayor relevancia ${ }^{17}$.

16 A la que se refiere Gustaaf Geeraerts contraponiéndola a la visión multilateral de la Unión Europea y señalando que la cercanía entre ambas aproximaciones no obsta la existencia de diferencias entre ellas de manera que la multipolaridad no es una garantía para el multilateralismo. GEERAERTS, G., "China, the EU, and the New Multipolarity», European Review, vol. 19, 2011, núm. 1, pp. 57-67, esp. p. 66. Por otra parte, el cambio de modelo auspiciado por el Acuerdo de París acarrea implicaciones en lo que se refiere al papel de las Naciones Unidas, en concreto en cuanto a la gestión de un nuevo esquema de cooperación descentralizado. A este respecto véase, por ejemplo, BodANSKY, D., BRUNNÉE, J. y RAJAMANI, L., International Climate Change Law, Oxford, Oxford University Press, 2017; o Dorsch, M. J. y Flachsland, Ch., «A Polycentric Approach to Global Climate Governance», Global Environmental Politics, vol. 17, mayo de 2017, núm. 2, pp. 45-64.

17 Ello no impide que en opinión de Sophie Lavalle y Sandrine Maljean la COP de 2009 tuviese algunos aspectos positivos que permiten no calificarla como un fracaso total, ya que sirvió para retomar el proceso de negociación tras un año delicado. Lavalle, S. y Maljean-Dubois, S., «L'Accord de Paris: fin de la crise du multilatéralisme climatique ou évolution en clair-obscur?", Revue Juridique de l'Environnement, núm. 1, marzo de 2016, pp. 19-36, esp. p. 25. Así, aunque el Acuerdo no responde al modelo multilateral su contenido es concretado y transformado en operativo por medio de una Decisión COP en la reunión siguiente en Cancún. Véase Decisión 1/CP.10, Acuerdos de Cancún: resultado de la labor 
Este menoscabo del carácter multilateral del modelo, que se añade al que se apuntó desde una perspectiva formal, trae el resultado conocido por todos de la ineficacia del esquema de cooperación internacional para lograr una reducción del volumen global de emisiones de GEI y por tanto limitar el incremento de temperaturas ${ }^{18}$. La consecuencia inmediata a la hora de diseñar un nuevo esquema, obligado por circunstancias inaplazables como se verá más tarde, es la necesidad de modificar el modelo de gestión climática para que sea global no solo formalmente sino también en lo sustantivo y que por tanto resulte efectivo.

\section{EL ACUERDO DE PARÍS: MOTIVOS PARA LA ESPERANZA EN EL PLANO PROCEDIMENTAL}

La oportunidad del necesario cambio de rumbo del modelo climático se presentaba con la adopción de un texto que remediase el fracaso de Copenhague, apenas matizado por la Enmienda de Doha. La necesidad de articular un esquema eficaz venía como consecuencia de dos realidades difícilmente cuestionables. La primera, de carácter jurídico, era el fin de la vigencia del primer periodo de cumplimiento del Protocolo de Kyoto el 31 de diciembre de 2012, ya señalado anteriormente, y la condición, en el mejor de los casos, de pasarela de lo acordado en Doha; la segunda era la constatación del agravamiento del problema. La primera realidad obligaba a la adopción de un texto jurídico-internacional pero la segunda iba más allá al imponer un contenido para ese Acuerdo que estableciese un nuevo modelo de gestión climática que superase las insuficiencias del anterior. En este apartado nos centraremos en el primer aspecto, dejando el segundo, relativo al fondo del Acuerdo, para el apartado siguiente.

El Acuerdo de París parecería responder plenamente a los retos apuntados, especialmente a tenor de los calificativos con los que era recibida su adopción, sirviendo como botón de muestra la consideración que el periódico británico The Guardian hacía de ese texto como el mayor éxito diplomático mundial ${ }^{19}$. Como se puede suponer, con tales expectativas el Acuerdo de

del Grupo de Trabajo Especial sobre la cooperación a largo plazo en el marco de la Convención (FCCC/ CP/10/7/Add.1, de 15 de marzo de 2011). A eso se añade que en opinión de las autoras el Acuerdo de Copenhague estructura, en el marco de la CMNUCC y junto al Protocolo de Kyoto, el periodo de 2020.

18 Procede recordar a estos efectos que 2016 se confirmaba como el año más caluroso de los que se tiene registro, con un aumento de la temperatura media global de aproximadamente 1.1 grados centígrados desde el periodo preindustrial. Véase Organización Meteorológica Mundial. Comunicados de prensa, disponible en https://public.wmo.int/es/media/comunicados-de-prensa/la-organización-meteorológica-mundial-confirma-que-2016-es-el-año-más (consultada el 22 de noviembre de 2017).

19 The Guardian, Paris climate change agreement: the world's greatest diplomatic success, lunes 14 de diciembe de 2015, disponible en http://www.theguardian.com/environment/2015/dec/13/paris-climate-deal-cop-diplomacy-developing-united-nations (consultada el 22 de noviembre de 2017). Una valoración que podría considerarse más realista que la expresada por medios de comunicación y políticos inmediatamente después de la adopción del Acuerdo era la realizada por Lavanya Rajamani al afirmar que se trata del resultado más ambicioso posible en un contexto político profundamente discordante. 
París tenía muy difícil hacer honor a lo que se le pedía y en efecto, como veremos más tarde, el examen de su contenido arroja sombras que analizaremos desde la perspectiva de su aportación al cambio de modelo de diplomacia climática, con el objetivo de clarificar su aportación en pos de un esquema ideal de gestión colectiva de un bien público global. Es decir, que lo que surge de la capital francesa supone sin ninguna duda un cambio de rumbo en el modelo de gestión del clima; de lo que se trata es de dilucidar si ese cambio va en el sentido de un reforzamiento de la multilateralidad, y a ser posible de la globalidad, o por el contrario se orienta en otra dirección. A continuación prestaremos atención tanto al desarrollo del propio proceso como a la forma del Acuerdo.

\subsection{El cambio de rumbo en cuanto al proceso negociador}

El necesario cambio de rumbo de la diplomacia climática parecía hacerse realidad en el propio proceso seguido para la adopción del Acuerdo. Frente a lo realizado en Copenhague, cuando los líderes políticos llegaban a la capital danesa con una negociación prácticamente por comenzar, ahora el proceso negociador se iniciaba de forma mucho más temprana y ya en la 17. ${ }^{\mathrm{a}}$ reunión de la COP, en diciembre de 2011, se creaba el Grupo de Trabajo Especial sobre la Plataforma de Durban para una acción reforzada, encargado de preparar el citado texto en un plazo determinado ${ }^{20}$. Este hecho no representaba por sí solo un progreso significativo respecto a lo ocurrido anteriormente puesto que también los trabajos que finalmente alumbraron el Acuerdo de Copenhague contaban con la fijación de un plazo de finalización, lo antes posible y a más tardar en 2015.

El verdadero cambio en la manera de proceder se materializaría a lo largo de todo el proceso negociador, que permitió llegar a la $20 .{ }^{a} \mathrm{COP}$, celebrada en Lima en diciembre de 2014, con un borrador de texto que, si bien se presentaba todavía muy abierto, quizá demasiado a la vista del elevado número de opciones existentes para cada cuestión, suponía un claro avance respecto al procedimiento seguido para Copenhague.

El cambio de rumbo se trasladaba incluso al plano de la entrada en vigor del Acuerdo. Los problemas que habían rodeado al Protocolo de Kyoto, y que se tradujeron en un lapso de tiempo de más de siete años para su entrada en vigor, desde su adopción el 11 de diciembre de 1997 hasta el 16 de febrero de 2005, no parecían existir en el caso del Acuerdo de París, hasta el punto de que en este aspecto sí que se optó por una de las opciones más avanzadas recogidas en los borradores previos. De esa forma la fecha inicialmente ba-

\footnotetext{
Rajamani, L., «Ambition and Differentiation in the 2015 Paris Agreement: Interpretative Possibilities and Underlying Politics», International and Comparative Law Quarterly, vol. 65, abril de 2016, pp. 493514, esp. p. 494.

20 Decisión 1/CP.17, Establecimiento de un Grupo de Trabajo Especial sobre la Plataforma de Durban para una acción reforzada (FCCC/CP/2011/9/Add.1, 15 de marzo de 2012, p. 2).
} 
rajada de 2020 era sustituida por la de la ratificación por 55 Estados parte en la CMNUCC que reúnan un 55 por 100 del volumen total de emisiones ${ }^{21}$. Esa circunstancia que en un principio podía llevar a pronosticar un retraso de la entrada en vigor del Acuerdo, al sustituir una fecha precisa, que parecía proporcionar una mayor certidumbre, por el cumplimiento de una condición cuyo logro se presenta como más variable en el tiempo, condujo sin embargo a que tras las ratificaciones de Canadá y la Unión Europea, ambas el 5 de octubre de $2016^{22}$, se alcanzase el umbral exigido para la entrada en vigor del Acuerdo, que se producía el 4 de noviembre, una fecha temprana en función de las expectativas. El motivo puede encontrarse en el cambio de posición de los dos emisores principales de GEI cuyo compromiso condiciona, en este caso y habida cuenta de las circunstancias para bien, el cumplimiento de una condición cualitativa basada precisamente en el volumen de emisiones. Precisamente ese dato está detrás del impacto causado por el Anuncio de la salida de Estados Unidos del Acuerdo de París, si bien sobre esa cuestión volveremos más tarde.

Pero todo tiene sus inconvenientes y esa rápida entrada en vigor ha tenido también al parecer algo de apresurada y ha cogido aparentemente desprevenidos a los gestores del Acuerdo. En este sentido debe tenerse en cuenta que en el texto adoptado en la capital francesa se diseña un sistema que se tiene que desarrollar en el futuro ${ }^{23}$, para lo que debían adoptarse una serie de decisiones de carácter reglamentario, fijadas para la primera y segunda COP posteriores a París ${ }^{24}$, que por el momento, y al menos en la primera ocasión, la que representó la 22. ${ }^{a}$ COP en Marrakech en diciembre de 2016, no ha sido debidamente aprovechada, quedando ese desarrollo reglamentario para la 23. ${ }^{a} \mathrm{COP}$, que

21 El borrador que se presentó a la COP de Lima planteaba hasta siete opciones distintas, girando varias de ellas en torno a esa fecha de 2020. Véase el Punto 95 del texto Elements for a draft negotiating text, anexo a la Decisión 1/CP.20, Llamado de Lima para la Acción Climática (FCCC/CP/2014/10/Add.1, 2 de febrero de 2015). Finalmente el texto final, tal como se recoge en el art. 21 del Acuerdo, optaría por la tercera de las opciones incluidas que, sin fijar cifras concretas, establecía que esa entrada en vigor tendría lugar sobre la base de: «A double threshold that includes both a number of Parties ratifying and a percentage of global emission reductions covered by the ratifying Parties/a minimum of global emissions from Parties".

22 Sobre el estado de ratificaciones del Acuerdo de París, véase Paris Agreement Status of Ratification, disponible en http://unfccc.int/paris_agreement/items/9444.php (consultada el 22 de noviembre de 2017).

${ }^{23}$ A ello alude Géraud de Lassus al definir el Acuerdo de París como una suerte de nueva convención marco que enuncia los fundamentos del régimen del clima post 2020 sin precisar todos los detalles. Una especie de juego de muñecas rusas con una convención marco —el Acuerdo- dentro de otra convención marco - la CMNUCC - De LASsus ST-Geniťs, G., "L'Accord de Paris sur le climat: quelques éléments de décryptage», Revue Québécoise de Droit International, vol. 28, 2015, núm. 2, pp. 27-51, esp. p. 34.

${ }^{24}$ Esta cuestión se aborda en la parte III de la Decisión 1/CP.21, relativa precisamente a las Decisiones para hacer efectivo el Acuerdo, que incluye peticiones dirigidas al Grupo de Trabajo Especial sobre el Acuerdo de París relativas a la preparación de documentos diversos referidos a todos los planos del régimen climático. Como muestra puede citarse, en relación con la mitigación, la petición de elaboración de orientaciones adicionales sobre las características de las Contribuciones Determinadas a nivel Nacional (CDN), para que la COP las examine y apruebe en su primer periodo de sesiones. Véase Decisión 1/CP.21, Aprobación del Acuerdo de París (FCCC/CP/2015/10/Add.1, de 29 de enero de 2016, párr. 26). 
tendrá lugar en Bonn en diciembre de 2017. Sin esos desarrollos reglamentarios es obvio que el Acuerdo no podrá desplegar todos sus efectos positivos.

\subsection{Por fin un texto jurídico-internacional en materia de cambio climático tras dos décadas}

La constatación de que las cosas parecían haberse hecho de otro modo no se limitaba al desarrollo del proceso negociador, sino que alcanzaba al resultado final del mismo, la adopción de un texto de carácter normativo. Esto, si bien ya no permitía evitar el problema del vacío jurídico experimentado por el retraso en la adopción del texto, que la Enmienda de Doha no ha sido capaz de colmar, al menos cumplía, aunque de forma tardía, con la exigencia de dar continuidad en el futuro al régimen climático internacional. Con la adopción del Acuerdo de París se terminaba con la incapacidad de la comunidad internacional para adoptar un texto internacional de carácter normativo en esta materia, al menos de alcance global, el último de los cuales, el Protocolo de Kyoto, se remontaba a prácticamente dos décadas atrás.

De hecho, ese cambio de rumbo relativo a la forma del resultado final se plasmaba ya en el propio mandato de Durban, que contemplaba la aprobación de un «protocolo, otro instrumento jurídico o una conclusión acordada con fuerza legal en el marco de la CMNUCC que sea aplicable a todas las Partes» ${ }^{25}$. Las distintas opciones posibles tenían en común su naturaleza jurídica, condición necesaria teniendo en cuenta que el objetivo era dar continuidad al régimen jurídico-internacional de lucha contra el cambio climático establecido por la CMNUCC y el Protocolo de Kyoto. Eso alejaba la posibilidad de optar por un texto político, carente de obligatoriedad jurídica, similar al Acuerdo de Copenhague de 2009, cuyo mandato, recogido en el Plan de Bali, no resultaba tan preciso en este punto de la naturaleza del resultado final del proceso negociador ${ }^{26}$.

Ese mandato sería cumplido stricto sensu por el Acuerdo de París, que, si bien comparte denominación con el alcanzado en Copenhague, es diferente en cuanto a su carácter jurídico frente a la ya mencionada naturaleza política del segundo. Sin embargo, si bien la forma es importante no es lo esencial, sino que se trata de una conditio sine qua non cuya aportación al cambio de rumbo exigido para la gestión de un bien público global se ve reducida si no va acompañada del fondo y en este sentido el Acuerdo de París, como se verá más adelante, no presenta un contenido demasiado exigente en cuanto a su nivel obligacional ${ }^{27}$.

\footnotetext{
25 Decisión 1/CP.17 (cit., nota 20, párr. 2).

${ }^{26}$ El Plan de Bali se limitaba a señalar el inicio de «un proceso global que permita la aplicación plena, eficaz y sostenida de la CMNUCC mediante una cooperación a largo plazo que comience ahora y se prolongue más allá de 2012», incluyendo como única referencia en cuanto a la forma la de «llegar a una conclusión acordada y de adoptar una decisión en su 15..$^{\circ}$ periodo de sesiones». Decisión 1/CP.13, Plan de Acción de Bali (FCCC/CP/2007/6/Add.1, párr. 1).

27 Esta cuestión es abordada por Daniel Bodansky quien, tras advertir que forma jurídica, obligatoriedad y aceptación doméstica no son necesariamente coincidentes, recuerda que el Acuerdo de
} 


\section{EL ACUERDO DE PARÍS: UN CAMBIO DE RUMBO ¿DECEPCIONANTE? EN LO SUSTANTIVO}

El optimismo, cuando no la euforia, con que fue recibido el Acuerdo de París, y que como se ha visto podía tener cierto fundamento sobre la base del análisis procedimental, resulta notablemente matizado cuando se aborda su contenido. Este parece presentar el texto surgido de la 21. ${ }^{\mathrm{a}} \mathrm{COP}$ como un paso más pero en ningún caso como el establecimiento definitivo de un modelo adecuado para la gestión del clima ${ }^{28}$. Es decir, que se trata de un nuevo intento de encontrar respuestas eficaces que, como el anterior, sigue descansando en la voluntad unilateral, incluso más que antes si cabe, de los Estados a la hora de contribuir al esfuerzo de mitigación. Es este factor el que conduce a calificar como decepcionante el Acuerdo de París, dada la urgencia del problema al que trata de dar respuesta, si bien dicho adjetivo se presenta entre interrogantes al considerar que pensar otra cosa hubiese pecado de optimismo excesivo dado el iter seguido hasta el momento en la negociación climática.

\subsection{El establecimiento de un modelo de gestión basado en la flexibilidad}

El Acuerdo de París, quizás como reacción al modelo anterior, hace de la flexibilidad su rasgo más característico, impregnando todos los planos del régimen en él establecido ${ }^{29}$, y teniendo un efecto positivo en algunos aspec-

\footnotetext{
París, aunque cumple la exigencia formal, siendo un tratado internacional, contiene un mix de previsiones obligatorias y no obligatorias. BodANSKY, D., "The Legal Character of the Paris Agreement», Review of European, Comparative and International Environmental Law, Special Issue: The Paris Agreement, vol. 25, julio de 2016, Issue 2, pp. 142-150. En esa misma línea Lavanya Rajamani distingue entre forma jurídica de un texto y naturaleza de sus previsiones, calificando el Acuerdo de París, en base a estas últimas, como un acuerdo voluntario o una declaración de buenas intenciones. El autor señala la coexistencia de obligaciones hard con otras soft, que hacen poco más que crear expectativas de buena fe de las Partes. A ello se añaden disposiciones no obligatorias, no usuales en previsiones operacionales de tratados pero que proporcionan un contexto valioso, construyen discursos y ofrecen garantías mutuas. RajAmani, L., "The 2015 Paris Agreement: Interplay Between Hard, Soft and Non-Obligations», Journal of Environmental Law, vol. 28, 2016, pp. 337-358. A este respecto cabe señalar que el peso de las obligaciones hard, tanto en mitigación como en financiación, resulta cuestionable como veremos más tarde en relación con la primera de esas dimensiones, mientras que la eventual aportación de las previsiones no obligatorias no parece muy adecuada cuando se afronta un problema que tiene en la urgencia de la respuesta una exigencia ineludible.

28 Esa aproximación positiva, aunque con matices que eviten la complacencia, es la sostenida por Sophie Lavalle y Sandrine Maljean, quienes destacan a favor de una visión optimista el lanzamiento de una nueva dinámica que rompe con un bloqueo de más de una década de negociaciones y que en el fondo supone un progreso que permite esperar un desarrollo menos caótico de las negociaciones climáticas. Pero advierten que el proceso sigue siendo frágil, por lo que el Acuerdo de París parece marcar el comienzo de una nueva era de diplomacia climática más que una culminación. LAVALLE, S. y MaLJeAn-Dubois, S., op. cit., nota 17, p. 36.

${ }_{29}$ En relación con este aspecto nos apoyaremos principalmente en el estudio de Marion LemoineSchonne: Lemoine-Schonne, M., «La flexibilité de l'Accord de Paris sur les changements climatiques», Revue Juridique de l'Environnement, vol. 41, 2016, núm. 1, pp. 37-55.
} 
tos mientras que en otros parece mutarse en ambigüedad o indefinición. La dimensión positiva sería la flexibilidad temporal, rasgo imprescindible para un texto que debe evolucionar de manera paralela al progreso de los conocimientos científicos y de los avances políticos y que por ello ha de ser necesariamente dinámico. De hecho, se trata de un rasgo que de una forma u otra se encuentra presente en los tratados medioambientales que siguen el esquema Convenio marco y protocolos de desarrollo, al que se ajusta el régimen climático ${ }^{30}$.

No tan benéfica resulta la flexibilidad normativa. Esta dimensión conduce en este caso en buena medida a desandar el camino que se recorrió con la adopción de un texto jurídico. En efecto el Acuerdo de París es un tratado internacional stricto sensu, y por tanto jurídicamente obligatorio, pero los términos empleados para la concreción de las obligaciones impuestas son tan imprecisos o difusos que ese nivel de obligatoriedad se desdibuja por el amplio margen de maniobra dejado a las Partes para el cumplimiento de dichas obligaciones ${ }^{31}$.

El resultado es que, si bien la flexibilidad del texto adoptado en la capital francesa tiene efectos tanto positivos como negativos, en el contexto del fenómeno al que se trata de dar respuesta, los inconvenientes parecen pesar más que las ventajas, impidiendo, o cuando menos retrasando, la puesta en marcha de forma inmediata de un esfuerzo de reducción de emisiones de GEI de intensidad suficiente para lograr el objetivo fijado por el art. 2.1.a) del Acuerdo de una limitación del incremento futuro de las temperaturas a 1,5-2 ${ }^{\circ}$ C. Esta valoración deriva de que el efecto benéfico de la flexibilidad temporal parece ceder respecto al obstáculo que representa la de carácter normativo, dando como resultado una indefinición excesiva para hacer frente a un problema urgente.

A ello contribuye además el carácter hipotético del efecto beneficioso que en el caso del régimen climático resulta de la flexibilidad temporal. Esta, que como ya se señaló permite al régimen jurídico establecido por los tratados medioambientales evolucionar de forma paralela a los descubrimientos de la ciencia, producirá mejores resultados cuanto más inmediatos sean los progresos políticos respecto a los avances científicos. Pero esta inmediatez no parece existir en lo que respecta al régimen climático internacional, tal como

${ }^{30}$ A ello se refiere Alexandre-Charles Kiss al subrayar el papel de la dimensión temporal en el Derecho internacional del medio ambiente como una de las razones de la existencia de este modelo, que permite el escalonamiento en el tiempo de la creación de normas y por tanto su mejor adaptación a la evolución tanto de las situaciones como de los conocimientos. KIss, A.-Ch., «Les traités-cadres: une technique juridique caractéristique du droit international de l'environnement», Annuaire Français de Droit International, vol. XXXIX, 1993, pp. 792-797.

31 Sobre esta paradoja señala Ángel Rodrigo que el Acuerdo de París por una parte presenta la condición de tratado pero por otra contiene un diferente grado de normatividad, siendo especialmente destacable lo relativo a las $\mathrm{CDN}$, concebidas como obligaciones de comportamiento y no de resultado. Rodrigo Hernández, A. J., «El acuerdo de París sobre el cambio climático: Entre la importancia simbólica y la debilidad sustantiva», en Martínez Capdevila, C. y Martínez Pérez, E. J. (dirs.), Retos para la acción exterior de la Unión Europea, Valencia, Tirant lo Blanch, 2017, pp. 409-431, esp. p. 410. 
vuelve a ponerse de manifiesto en el caso del Acuerdo de París, especialmente en relación con una de las manifestaciones de la flexibilidad temporal, la del mecanismo de revisión quinquenal contemplado en el art. 4.9 del Acuerdo, que en un escenario ideal llevaría a una adecuación de los compromisos políticos para responder de forma suficiente a lo que resulte de la observación científica del fenómeno climático. Sin embargo, la flexibilidad normativa que se establece en el Acuerdo de París no garantiza ese paralelismo de forma automática en la medida en que de los términos empleados no puede deducirse una obligación para las Partes de ajustar sus compromisos a los datos que ofrezca la ciencia respecto a la evolución del calentamiento global.

Esa transformación de la flexibilidad en ambigüedad, quizá excesiva, es decir la imposición de la flexibilidad normativa sobre la temporal, se proyecta de manera principal en el plano fundamental del mecanismo de gestión climática, el de la mitigación, alcanzando no solo al citado procedimiento de revisión sino en su conjunto al régimen de asunción de obligaciones asumidas por las Partes desde el primer momento. Es precisamente en este punto en el que nos detendremos para considerar que el cambio de rumbo del modelo de gestión del clima se aleja del multilateralismo para inclinarse de manera definitiva hacia la multipolaridad, a través de una individualización del sistema de asunción de compromisos de reducción de emisiones de GEI por las Partes ${ }^{32}$.

\section{2. ¿Flexibilidad o ambigüedad del nuevo esquema de atribución de obligaciones en materia de mitigación?}

El nuevo esquema de atribución de obligaciones de reducción de emisiones de GEI, concretado principalmente en los arts. 3 y 4 del Acuerdo, constituye el cambio de rumbo más claro, o cuando menos el más visible, respecto del escenario anterior ${ }^{33}$. El modelo centralizado de asignación de obligaciones del esquema anterior se sustituye por otro que en principio podríamos calificar como descentralizado. El motivo podría encontrarse en las limitaciones ya apuntadas del mecanismo conocido como top down, en especial la ineficacia desde la perspectiva de la reacción contra el calentamiento global que la asignación de compromisos por la COP, y por tanto, de naturaleza

\footnotetext{
32 A ello se refieren Marion Lemoine y Anne-Sophie Tabau al advertir de la sustitución de la lógica bipolar anterior, materializada en la distinción entre países Anexo I y no Anexo I, por otra multipolar, descrita por estas autoras como de autoidentificación. LEMOINE, M. y TABAU, A.-S., "La conférence climat de Lima: Aller de l'avant en tirant les enseignements du passé», Revue Juridique de l'Environnement, núm. 2, 2015, pp. 301-328, esp. p. 319.

${ }_{33}$ Cambio cuya complejidad queda demostrada por el largo camino seguido para su establecimiento, que tiene su primera manifestación en el Acuerdo de Copenhague, adoptado en la 15. ${ }^{\text {a }}$ COP (FCCC/CP/2009/11/Add.1, de 30 de marzo de 2010, p. 6, párrs. 4 y ss.) incluyéndose en ese momento en el programa de trabajo que finalmente conduciría a su consagración en el Acuerdo de París, pudiendo citarse de forma especial su mención en el marco de la 19. ${ }^{a}$ COP, en Varsovia en 2013. Véase Decisión 1/CP.19, Intensificación de los trabajos relativos a la Plataforma de Durban [FCCC/CP/2013/10/Add.1, de 31 de enero de 2014, párr. 2.b)].
} 
multilateral, al menos formalmente, había puesto de manifiesto. A ello contribuían ciertos aspectos también señalados y que ahora simplemente recordamos, por una parte, la existencia de un sistema de emisiones exentas -las de los Estados no incluidos en el Anexo I-, a lo que se añadía el juego de la soberanía estatal, materializado en la no participación de Estados Unidos en el Protocolo de Kyoto, a la que se sumaron otros — Rusia, Canadá o Japóncon ocasión del segundo periodo de cumplimiento del mismo establecido en la Enmienda de Doha. A todo eso deben añadirse las deficiencias mostradas en la práctica por ese modelo de gestión, que se apartaba de la lógica multilateral para acercase más bien a un esquema multipolar, especialmente visible en el proceso de adopción del Acuerdo de Copenhague.

El recordatorio de esos límites debería servir para fijar los vectores del nuevo esquema de diplomacia climática evitando, en la medida de lo posible, esos obstáculos. Es evidente que el relativo al papel de la soberanía estatal resulta de muy difícil elusión en el actual estado de la sociedad internacional, como se ha puesto de manifiesto con el anuncio por Donald Trump de la salida de los Estados Unidos del Acuerdo ${ }^{34}$. Pero los otros inconvenientes del esquema anterior, los relativos a la existencia de emisiones exentas y a un funcionamiento práctico que no se corresponde con una lógica multilateral, sí que parecían susceptibles de corrección en un nuevo modelo de gestión climática.

34 El anuncio realizado el 31 de mayo por el nuevo presidente de Estados Unidos, seguido el 4 de agosto de 2017 por la comunicación oficial del representante de los Estados Unidos en las Naciones Unidas al Secretario General, en su condición de depositario del Acuerdo (disponible en https://treaties. un.org/doc/Publication/CN/2017/CN.464.2017-Eng.pdf; consultada el 22 de noviembre de 2017), no era sino la confirmación de su posición tanto antes como durante la campaña electoral, con el famoso Chinese hoax como argumento, y repetido más tarde por ejemplo durante la cumbre del G7 de Taormina, ya como presidente en ejercicio. En todo caso, y aunque sea de forma breve, debe apuntarse que el impacto de esa salida, aun siendo obviamente una muy mala noticia, no parece que pueda equipararse a la paralización de la diplomacia climática ocasionada por el rechazo de ese mismo Estado a la ratificación del Protocolo de Kyoto. A esa conclusión conducen diversos factores, tanto de carácter doméstico como externos a ese país. Entre los primeros merecen destacarse el esfuerzo de mitigación que se viene desarrollando desde ciertos Estados, entre los que cabe destacar el caso de California, y ciudades como, por ejemplo, Los Ángeles o Washington. A ello se suma la postura de la industria, incluyendo el sector de los combustibles, manifestada con ocasión del anuncio de salida por el Presidente, considerada por empresas como Exxon Mobil, Chevron o General Electric, entre otros, como una mala decisión que no toma en cuenta la inversión ya realizada en tecnologías bajas en carbono ni las oportunidades que se abren en el ámbito energético, en concreto en lo que respecta a la inversión en energías renovables, que la economía norteamericana no parece dispuesta a dejar pasar sin más. En el plano externo el cambio es aún más evidente dado que la desaparición del esquema bipolar de obligaciones anterior hace desaparecer el argumento utilizado por la Administración Bush para el rechazo a ratificar Kyoto. A eso se suma que China, por razones que van desde su propia necesidad hasta la oportunidad de reforzar su liderazgo en la diplomacia climática, pasando por el intento de aprovechar los beneficios económicos de dedicar esfuerzos a sectores como el de las energías renovables, ha hecho saber que mantiene su compromiso con el nuevo régimen de lucha contra las emisiones de GEI. Esa diferencia en el contexto internacional se materializaba en la cerrada defensa del Acuerdo con ocasión de la 22. ${ }^{\text {a }}$ COP, coincidiendo con las elecciones que auparon a Trump a la Presidencia, llegando en la Marrakech Action Proclamation for our Climate Change and Sustainable Development a calificarse como irreversible el impulso recibido por la lucha contra el cambio climático. A este respecto véase, por ejemplo, WAGNER, G. y KeITH, D., "Cop22 after Trump. The Good and Bad News for Climate Change», Foreign Affairs, 2016, pp. 1-9 (disponible en https://www.foreignaffairs.com/articles/2016-11-21/cop22-after-trump; consultada el 22 de noviembre de 2017). 
El Acuerdo de París responde al primero de esos aspectos operando una desaparición del sistema de emisiones exentas en la medida en que, conforme a su art. 3, las obligaciones ya no se circunscriben a las Partes del Anexo I. Con ello se termina con la lógica simplista que antes presidía el esquema de atribución de obligaciones de reducción de emisiones de GEI que, como ya se apuntó, estaba en la base de la ineficacia misma del modelo de gestión del clima. Pero curiosamente esa desaparición de emisiones exentas no se traduce en un reforzamiento del multilateralismo sino, tal como se apuntó con anterioridad, de la multipolaridad. Ello además de que la inexistencia de países liberados per se del esfuerzo de mitigación no supone una desaparición total de la división bipolar entre países desarrollados y en desarrollo, que de alguna manera permanece presente en el régimen climático internacional ${ }^{35}$.

En realidad, la persistencia de esa distinción entre países desarrollados y en desarrollo no es en sí misma algo perjudicial, ni su eliminación constituye un objetivo primordial, siempre que la misma no se proyecte al esfuerzo de mitigación, implicando la existencia de un permiso para seguir emitiendo GEI a algunas de las Partes. Y esto si bien no se recoge de forma expresa como en el esquema anterior, no deja de tener ciertas referencias indirectas, especialmente en la mención del art. 4.1 a que los países en desarrollo tardarán más en alcanzar su punto máximo de emisiones, de donde resulta implícitamente la posibilidad de seguir incrementando estas hasta ese momento ${ }^{36}$.

El grado de respuesta es incluso menor en el otro aspecto que debería ser objeto de modificación en el nuevo régimen climático, impidiendo que el multilateralismo formal, aunque con las limitaciones apuntadas en ese plano, no devenga en multipolarismo como consecuencia de su aplicación práctica. El Acuerdo de París afronta ese desafío mediante la instauración de una lógica descentralizada en cuanto al mecanismo de asunción de compromisos

35 A ello se refiere Géraud de Lassus advirtiendo que el principio de las responsabilidades comunes pero diferenciadas no desaparece, sino que se transforma. Así ese Principio sigue estando presente de forma expresa en el Acuerdo, pudiendo citar con carácter horizontal la mención del art. 2.2, pero se modifica mediante una diferenciación del lenguaje, que obliga a los países desarrollados y anima a los países en desarrollo. En este sentido es de destacar la diferencia que se recoge en el art. 4.4 entre la mención a que los primeros «deberían seguir encabezando los esfuerzos, adoptando metas absolutas de reducción de emisiones para el conjunto de la economía» y la que se refiere a que los países en desarrollo «deberían seguir aumentando sus esfuerzos de mitigación», alentando a esos países a que, "con el tiempo, adopten metas de reducción o limitación de las emisiones para el conjunto de la economía, a la luz de las diferentes circunstancias nacionales». DE LASsus ST-GENIÈs, G., op. cit., nota 23, pp. 44 y ss. En esa misma línea Lavanya Rajamani distingue las referencias a los países desarrollados en términos de mandato y las dirigidas a los países en desarrollo concebidas más como esperanza que como obligación. RAJAMANI, L., op. cit, nota 19, pp. 507 y ss.

36 Sobre ese particular afirma Alejandro Lago que el principal elemento de quiebra respecto del Protocolo de Kyoto, la no participación de los países emergentes, se ha resuelto en falso, puesto que no está claro que se pueda determinar de forma precisa el momento en que la obligación de reducción de emisiones se aplique para algunos países, al menos para los emergentes. El resultado es que la limitada incorporación de los países en desarrollo se ha llevado a cabo a costa de eliminar cualquier objetivo cuantitativo agregado y menoscabando incluso los objetivos previos al no establecer siquiera un año determinado de referencia. Lago CandeIRA, A., «El Acuerdo de París. ¿Solución al cambio climático o el principio del fin del actual multilateralismo ambiental?», Ambienta. La revista del Ministerio de Medio Ambiente, vol. 114, 2016, pp. 20-32, esp. p. 31. 
en materia de mitigación. El problema es que en el nuevo sistema bottom up el multilateralismo incluso formal se reduce de manera que las obligaciones ya no son asignadas por la COP, rasgo sobre el que se apoyaba la naturaleza multilateral del esquema anterior, sino que son los propios Estados los que, a través de las CDN, asumen el protagonismo de una manera muy pronunciada $^{37}$.

De este simple hecho, y a salvo de precisiones que posteriormente se realizarán, podemos ya concluir que el cambio de rumbo del nuevo modelo aleja a este del carácter multilateral para acercarlo más bien a un esquema individualizado ${ }^{38}$.

Desde la perspectiva de la eficacia del nuevo modelo para articular una reacción adecuada al calentamiento global destaca la falta de coherencia que exhibe el Acuerdo que por una parte consagra una ambición, limitada, de lograr el objetivo antes señalado de reducir a $1,5^{\circ} \mathrm{C}$ el incremento de temperaturas mientras que por otra no fija un plazo para el logro del objetivo. En este punto la flexibilidad normativa opera de manera perversa puesto que el Acuerdo de París ni siquiera contempla la vuelta a una senda de reducción de emisiones de GEI de forma inmediata, sino que, conforme al art. 4.1, lo fija en un futuro indefinido tal como resulta del objetivo de que las emisiones de GEI «alcancen su punto máximo lo antes posible». Indefinición en cuanto a la fijación de plazos que solo se reduce, y no demasiado, al señalar la pretensión de alcanzar un equilibrio entre las emisiones antropógenas por las fuentes y la absorción antropógena por los sumideros «en la segunda mitad del siglo».

La conclusión es que se abre la puerta de forma todavía de manera más acusada, en cuanto que se produce dentro del propio sistema, es decir de manera legal, a comportamientos de free rider o polizón. Ahora los Estados que quieran beneficiarse de un comportamiento de esa naturaleza, éticamente reprobable pero perfectamente legal como ya se ha dicho, basta que se autoimpongan compromisos limitados de reducción de emisiones, haciendo recaer el peso de la gestión común sobre las espaldas de los demás Estados, y obteniendo de ello una doble ventaja, la que resulta del progreso en la reacción contra el calentamiento global, del que también ellos se benefician aunque no hayan aportado su contribución, y la de los menores costes a afrontar como consecuencia de su limitada ambición.

Pero el margen de libertad que se reconoce a los Estados en el nuevo sistema no se limita a la autoasignación de compromisos vía las respectivas CDN, sino que se amplía por la inexistencia de auténticos límites a esa flexibilidad

\footnotetext{
37 Aspecto subrayado por Géraud de Lassus al recordar la gran deferencia que el Acuerdo de París observa hacia las elecciones de los miembros del régimen climático internacional, dejando a estos un amplio margen de maniobra que se concreta tanto en la determinación de sus niveles de esfuerzo de mitigación, a través del mecanismo de la CDN, como en la identificación del tipo de medidas a adoptar para esa atenuación. De LAssus St-Geniès, G., op. cit., nota 23, pp. 41 y ss.

38 Sobre la naturaleza ambivalente de los compromisos asociados a las CDN, recuerda Ángel Rodrigo que se trata de obligaciones formalmente multilaterales, en cuanto aplicables a todos conforme al art. 3, pero de determinación unilateral. RodRIGo HeRNÁNDEZ, A. J., op. cit., nota 31, p. 420.
} 
en el sentido de fijar algún tipo de suelo en cuanto a la ambición de los Estados. La flexibilidad normativa se hace sentir de nuevo de forma negativa limitándose el art. 4.3 del Acuerdo a señalar que la cuota de contribución al esfuerzo colectivo consagrada en la correspondiente CDN representará la «mayor ambición posible».

$\mathrm{Y}$ en ese mismo sentido pueden mencionarse otras manifestaciones del inconveniente que para la eficacia del sistema resultan de la citada flexibilidad normativa, que incrementan su impacto en la naturaleza multilateral del mismo, orientándolo más bien hacia una individualización de la asunción de compromisos en materia de mitigación, a través del esquema de autoasignación ya apuntado. Especialmente relevante en este sentido es lo que se refiere al establecimiento de lo que podríamos calificar como un sistema de armonización contable de las $\mathrm{CDN}$, clave para medir hasta qué punto la suma de los esfuerzos libremente determinados a nivel nacional, en la que ahora se traduce el esfuerzo global, es suficiente para responder eficazmente al fenómeno que se trata de contrarrestar.

En ese sentido el art. 4.8 del Acuerdo de París establece que cada CDN deberá ir acompañada de «la información necesaria a los fines de la claridad, la transparencia y la comprensión, con arreglo a lo dispuesto en la Decisión 1/CP.21 y en toda decisión pertinente que adopte la Conferencia de las Partes en calidad de reunión de las Partes en el presente Acuerdo». Lo que se completa en la citada Decisión 1/CP.21, si bien el lenguaje empleado, de nuevo la flexibilidad normativa, no parece imponer obligaciones en este sentido ${ }^{39}$. Eso supone que el amplio margen de acción reconocido a las Partes se extiende a cuestiones como, por ejemplo, la fijación del año de base para medir la reducción de emisiones autoasignada, lo que repercute en la magnitud del esfuerzo asumido por cada Estado, puesto que cuanto más tardío sea el año elegido menor será la reducción de las emisiones de GEI, que se han ido incrementando progresivamente, enmascarando así el esfuerzo reducido que un Estado decida llevar a cabo, al dificultar la comparación con el llevado a cabo por otros. De hecho, ese margen de libertad se ha materializado en la práctica en las distintas CDN, pudiendo distinguir casos como los de la Unión Europea

39 La Decisión 1/CP.21 señala que: «Conviene en que la información que comuniquen las Partes al presentar sus contribuciones determinadas a nivel nacional, a fin de facilitar la claridad, la transparencia y la comprensión, podrá incluir, entre otras cosas y según proceda, información cuantificable sobre el punto de referencia (con indicación, si corresponde, de un año de base), los plazos y/o periodos para la aplicación, el alcance y la cobertura, los procesos de planificación, los supuestos y los enfoques metodológicos, incluidos los utilizados para estimar y contabilizar las emisiones antropógenas de gases de efecto invernadero y, en su caso, las absorciones antropógenas, y una explicación de los motivos por los que la Parte considera que su contribución determinada a nivel nacional es justa y ambiciosa, a la luz de sus circunstancias nacionales, y de la forma en que contribuye a la consecución del objetivo de la Convención enunciado en su art. 2». Decisión 1/CP.21 (cit., nota 24, párr. 27). La cursiva incluida por nosotros pone de manifiesto la proyección de la flexibilidad normativa en este punto. La obligación de información que deben suministrar las Partes se completa con lo recogido en el art. 13.7 del Acuerdo, especialmente en su parágrafo $b$ ) que recoge que cada Parte deberá proporcionar «la información necesaria para hacer un seguimiento de los progresos alcanzados en la aplicación y el cumplimiento de su contribución determinada a nivel nacional en virtud del art. 4». 
o Rusia, que establecen 1990, frente a otros como los de los dos emisores de GEI principales, Estados Unidos y China que optan por 2005 como año de referencia para medir su reducción de emisiones.

Las consecuencias negativas resultantes de la ambigüedad normativa se extienden al mecanismo de revisión, uno de los instrumentos incluidos en el Acuerdo que reflejan la influencia positiva de la flexibilidad temporal con la que se pretende una mejor adaptabilidad del régimen jurídico tanto a los avances científicos como a la voluntad política. Como ya se dijo anteriormente el problema es que la evolución de esa voluntad no guarda el debido paralelismo con lo que la ciencia nos va ofreciendo acerca del fenómeno del calentamiento global. Si eso fuera así debería preverse, a la luz del agravamiento constante del problema, que las Partes modificasen al alza, y de manera sustancial, sus compromisos en futuras revisiones de sus CDN, pero también aquí la flexibilidad, o de manera más precisa la ambigüedad, normativa juega en sentido negativo, extendiendo también en este plano un margen de acción a las Partes que no garantiza que esa intensificación futura vaya a producirse. No obstante, para no hacer un ejercicio de adivinación habrá que esperar para ver si ese pronóstico se cumple, siendo el primer momento el diálogo facilitador previsto para $2018^{40}$, y posteriormente el primer balance mundial que llevará a cabo la COP y que conforme al art. 14.2 tendrá lugar en 2023. La duda es si teniendo en cuenta la evolución del calentamiento global no se habrá perdido un tiempo precioso para articular una respuesta que reduzca sus efectos negativos ${ }^{41}$.

La afirmación de que el mecanismo de revisión periódica de las CDN no garantiza una evolución de la voluntad de los Estados paralela a las exigencias que resultan de la observación científica se apoya en que también aquí se reproduce el efecto negativo de la ausencia de una exigencia mínima respecto del nivel de esfuerzo de los Estados en posteriores adaptaciones de sus correspondientes CDN. Así el art. 4.3 del Acuerdo señala como única condición que las posteriores CDN representen «una progresión» con respecto a la que esté vigente para esa Parte. Con esa exigencia se garantiza la progresividad en cuanto a la intensidad del esfuerzo de cada Parte en la reducción de sus emisiones de GEI pero puede tener como efecto perverso incentivar una minoración del esfuerzo inicial, logrando con ello un margen mayor de manio-

40 Cuando las Partes harán un balance de sus esfuerzos colectivos y se determinará el avance del objetivo en el largo plazo, orientando de esa forma la preparación de las CDN futuras. Véase Decisión 1/CP.21 (cit., nota 24, párr. 20).

41 A ello se refieren Sophie Lavalle y Sandrine Maljean recordando que, conforme al Informe del Programa de las Naciones Unidas para el Medio Ambiente de 2015, para tener posibilidades, una sobre dos, de limitar el calentamiento a $1,5^{\circ} \mathrm{C}$ en 2100 solo deberían emitirse 450 billones de toneladas de $\mathrm{CO}_{2}$, pero los compromisos de los Estados en sus CDN llevan a que ese volumen se haya emitido ya en 2024, lo que deja muy poco margen salvo un golpe drástico de timón. LAVALLE, S. y MALJEAN-DuBoIs, S., op. cit., nota 17, p. 30. La tendencia insuficiente del esfuerzo global de mitigación es también advertida por la Decisión 1/CP.21 que observa con preocupación la insuficiencia del esfuerzo agregado al que conducen las $\mathrm{CDN}$ presentadas para alcanzar el objetivo de aumento de la temperatura media mundial por debajo de los $2{ }^{\circ} \mathrm{C}$, que en palabras de la COP «requerirá un esfuerzo de reducción de emisiones mucho mayor que el que suponen las CDN». Decisión 1/CP.21 (cit., nota 24, párr. 17). 
bra en posteriores revisiones de cada una de las contribuciones nacionales al esfuerzo de mitigación.

\subsection{El papel del voluntarismo en la contribución al esfuerzo de mitigación}

De lo dicho hasta ahora se deduce que el cambio de rumbo operado en el modelo de gestión climática no parece garantizar la superación de uno de los problemas esenciales del esquema anterior, el del condicionamiento de su eficacia en último término a la voluntad de los Estados de cumplir con unas obligaciones cuyo contenido les concedía la posibilidad de optar por grados o formas distintas de observancia. El obstáculo que de ello resulta para la gestión de un bien público global como es el clima se mantiene, incluso si cabe con mayor relevancia ${ }^{42}$. En efecto, el nuevo modelo basado en la asunción de compromisos de mitigación de manera individual por cada Estado se somete en cuanto condición de eficacia a que el esfuerzo agregado de reducción de emisiones de GEI sea suficiente para alcanzar el umbral de incremento de las temperaturas por debajo de los 1,5 o $2{ }^{\circ} \mathrm{C}$, reflejado en el Acuerdo de París. $\mathrm{Y}$ eso solo es posible si los Estados usan el amplio margen de libertad que se les concede teniendo en mente la necesidad de alcanzar ese umbral colectivo y se autoimponen unas obligaciones de reducción de emisiones lo suficientemente significativas, especialmente los mayores emisores.

Es decir, que en este punto parece haberse operado un giro de $360^{\circ}$, volviendo al punto de partida en la medida en que la eficacia del esquema de cooperación climática sigue dependiendo en último término de la voluntad de las Partes. Y ello con un agravante respecto al modelo anterior, en el que el papel de esa voluntad estatal resultaba, en el caso de las Partes del Anexo I, de la insuficiencia de mecanismos de sanción en caso de incumplimiento de las obligaciones que se les habían asignado de forma centralizada; mientras que, en el caso de los países no Anexo I, el papel de esa conciencia climática era todavía más acusado, ya que sus esfuerzos de reducción de emisiones tenían un carácter puramente voluntario al no estar sometidos a ningún tipo de obligación jurídica al respecto. Por su parte, el nuevo modelo parece extender el panorama señalado para los países no Anexo I, siguiendo la terminología del modelo anterior, puesto que en el nuevo esquema de

42 El papel clave del factor de la voluntad política en el nuevo esquema de cooperación es subrayado por Alejandro Lago, advirtiendo incluso su mayor trascendencia respecto del modelo previo. Para este autor si tras el fracaso de Copenhague se consideraba que se había perdido una década completa (2010-2020) a nivel internacional en materia de cambio climático, la adopción del Acuerdo de París parece certificar que se da por perdida ya no la siguiente década — lo cual parece seguro con las CDN presentadas por las Partes- sino la primera mitad del siglo XXI. El Acuerdo supone, en su opinión, la consagración del mínimo común denominador absoluto en materia de cambio climático: que cada uno haga lo que buenamente pueda, o lo que es peor, añadimos nosotros, lo que cada uno quiera o mejor se adapte a su estrategia. Ello lleva al autor a una conclusión pesimista respecto a la aportación del cambio de rumbo sobre el multilateralismo climático, que con este Acuerdo parece haber tocado fondo. Lago CANDEIRA, A., op. cit., nota 36, p. 31. 
autoasignación de las obligaciones de reducción de emisiones nada impide que los Estados exhiban una ambición limitada en su contribución al esfuerzo colectivo, que difícilmente podrá considerarse vulnerando los mandatos vagos y difusos recogidos al respecto en el Acuerdo y a los que se ha hecho mención con anterioridad. De hecho, esa parece ser de momento la realidad, tal como se reconoce en el propio Acuerdo y por la COP cuando advierten de la insuficiencia del esfuerzo agregado de reducción de emisiones de GEI que resulta de las CDN presentadas hasta el momento por los Estados, que se sitúan en una trayectoria alejada de esa limitación del aumento de las temperaturas de $2{ }^{\circ} \mathrm{C}^{43}$.

El papel de la voluntad política de cumplir con los compromisos autoasignados resulta reforzado por la existencia de un mecanismo débil de sanción de un posible incumplimiento. En realidad, este aspecto se encontraba ya presente en el esquema anterior, pero lo cierto es que no puede decirse que el Acuerdo de París haya mejorado la situación.

Debe reconocerse que no se trata de un escollo fácil de salvar y que, de manera más o menos aguda, es un lugar común en el ámbito de la gestión de los bienes comunes. La interdependencia existente en cuanto al disfrute de esos bienes conduce a que el objetivo primero en casos de incumplimiento de las respectivas obligaciones sea el de la terminación de esa situación, que repercute de forma negativa en los demás usuarios de dicho bien, quedando la dimensión sancionadora en un segundo plano en la medida en que no aporta necesariamente una mejora inmediata en cuanto al disfrute del bien por los demás usuarios del mismo sino simplemente el castigo al incumplidor. A ello se añade que, en el contexto de una sociedad descentralizada como es la sociedad internacional, los Estados son particularmente reacios al establecimiento de mecanismos sancionadores muy exigentes a los que ellos mismos han de someterse. La aplicación de esa lógica al régimen climático supone que cualquier incumplimiento de las obligaciones de reducción de emisiones de GEI tiene como principal consecuencia negativa una reducción de los efectos de la reacción global frente a ese fenómeno.

Volviendo a la conclusión de que el actual esquema descentralizado no supone una mejora de la situación respecto al anterior mecanismo centralizado en lo relativo al procedimiento de sanción de los incumplimientos ${ }^{44}$, debe

43 La COP advierte que el actual escenario conduce a un nivel de emisiones de 55 gigatoneladas en 2030 lo que supera claramente el límite de 40 gigatoneladas que permitiría mantener el aumento de la temperatura mundial por debajo de los $2{ }^{\circ} \mathrm{C}$. Véase Decisión 1/CP.21 (cit., nota 24, párr. 17).

${ }^{44}$ La CMNUCC y el Protocolo de Kyoto contienen mecanismos débiles de exigencia de responsabilidades por incumplimiento cuyo objetivo, de conformidad con lo apuntado en relación con la gestión de bienes públicos globales, es incitar al Estado incumplidor a corregir el incumplimiento de sus compromisos. Para ello se establece un Grupo de facilitación, que asume funciones de asesoramiento a las Partes en la aplicación del Protocolo, y otro Grupo de control del cumplimiento, en principio encargado de la reacción frente a posibles fallas en el mismo, para lo que tiene a su disposición un abanico de medidas correctivas que en el plano de la mitigación incluyen la deducción de la cantidad atribuida a esa Parte para el segundo periodo de compromiso, de un número de toneladas igual a 1,3 veces la cantidad en toneladas de las emisiones excedentarias, así como la elaboración de un Plan de 
señalarse que el Acuerdo de París opta por la alternativa menos exigente de todas las incluidas en el texto objeto de negociación ${ }^{45}$. El resultado es que el art. 15 del Acuerdo consagra un mecanismo de aplicación poco constrictivo señalándose que el comité encargado de esta tarea estará compuesto por expertos y tendrá un carácter facilitador, funcionando de manera transparente, no contenciosa y no punitiva.

\section{CONCLUSIONES}

Desde una perspectiva general puede concluirse que el Acuerdo adoptado en la COP de París presenta un balance desigual que incluye luces y sombras. La valoración final del mismo está como es obvio sujeta a que la aproximación se haga desde una perspectiva optimista o pesimista, si bien dada la urgencia del problema, que resulta de los datos científicos y que puede preverse que será confirmada por el próximo Informe del Panel Intergubernamental para el Cambio Climático, no puede ocultarse que en este caso la segunda aproximación parece más ajustada a la realidad del fenómeno que la primera. Podría decirse que mientras el esquema de cooperación climática sigue una progresión aritmética el agravamiento del fenómeno del calentamiento global lo hace en una progresión geométrica, lo que da como consecuencia que si bien puede aceptarse que seguimos avanzando no lo hacemos al ritmo necesario, por lo que el objetivo fijado parece alejarse progresivamente. Es decir, que el Acuerdo de París es un paso más que como aporte principal presenta el mantenimiento del esfuerzo de mitigación. No puede negarse que eso es un avance dado el estadio de esa cooperación climática en los últimos años, especialmente la incapacidad para adoptar textos jurídicos. Pero lo que resulta en términos de obligaciones del contenido del Acuerdo no puede justificar la más mínima complacencia, dado que el margen de maniobra concedido a las Partes no garantiza una intensidad en el esfuerzo colectivo coherente con la limitación del

acción para el cumplimiento y la suspensión del derecho a hacer transferencias en virtud del art. 17 del Protocolo hasta que se restablezca el derecho de esa Parte. Véase Decisión 24/CP.7, Procedimientos y mecanismos relativos al cumplimiento previstos en el Protocolo de Kyoto (FCCC/CP/2001/13/Add.3, 21 de enero de 2002, pp. 72 y ss.) y Decisión 27/CMP.7, Procedimientos y mecanismos relativos al cumplimiento previstos en el Protocolo de Kyoto (FCCC/KP/CMP/2005/8/Add.3, 30 de marzo de 2006, pp. 112 y ss.). La misma conclusión resulta en el plano del arreglo de controversias en el que el art. 14.2 de la CMNUCC, al que remite el art. 19 del Protocolo de Kyoto, exige el acuerdo de las dos Partes en la controversia, lo que en el supuesto de un bien de interés general plantea el problema de la identificación del potencial demandante, dado que el perjuicio resultante del incumplimiento tiene un carácter general que en principio haría de esa reducción de emisiones una suerte de obligación erga omnes que legitimaría a cualquier otro Estado a solicitar la responsabilidad del incumplidor.

45 El texto surgido de la reunión de junio del Grupo de trabajo incluía seis propuestas que iban en orden decreciente de intensidad desde el establecimiento de un tribunal internacional de justicia climática para supervisar, controlar y sancionar posibles incumplimientos de las obligaciones que resultan de este Acuerdo y de la CMNUCC hasta la referencia a que no se requieren previsiones específicas al respecto. Véase Streamlined and consolidated text. Version of 11 June 2015. Ad Hoc Working Group on the Durban Platform for Enhanced Action, Second session, part nine, 1-11 June 2015, Bonn, Germany, pp. 77 y ss. Disponible en http://unfccc.int/files/bodies/awg/application/pdf/adp2-9_i3_11jun2015t1630_ np.pdf (consultada el 22 de noviembre de 2017). 
aumento de temperaturas globales en los umbrales fijados en el propio Acuerdo para que los efectos negativos del problema no sean demasiado graves.

La conclusión es más desalentadora en relación con la cuestión objetivo de estudio. El nuevo esquema bottom up no refuerza el multilateralismo del sistema climático, considerado como el esquema ideal para la gestión de un bien público global. En lugar de eso el Acuerdo de París establece un esquema individualizado, propio como se ha dicho de una aproximación multipolar más que multilateral. La amplia libertad de la que disfrutan los Estados para fijar metas de reducción de emisiones de GEI, sumada a factores como la inexistencia de mecanismos de sanción en caso de incumplimiento, permite afirmar que el texto surgido de la 21. ${ }^{a} \mathrm{COP}$ contempla un modelo de gestión en el que el esquema multilateral no pasa de asumir la función de impulso y coordinación de los respectivos compromisos individuales, y en ese contexto la efectividad de la reacción frente al problema está más condicionada si cabe por la voluntad política de los Estados, lo que como la experiencia ha demostrado, incluso muy recientemente, no parece suficiente para garantizar el cumplimiento de los objetivos.

\section{RESUMEN \\ EL ACUERDO DE PARÍS DE DICIEMBRE DE 2015: LA SUSTITUCIÓN DEL MULTILATERALISMO POR LA MULTIPOLARIDAD EN LA COOPERACIÓN CLIMÁTICA INTERNACIONAL}

El Acuerdo de París rompe la dinámica perversa en que había entrado la cooperación climática internacional tras los intentos fallidos de Copenhague y Doha. Esta circunstancia es la única que justifica el entusiasmo con el que fue recibido. Sin embargo, la lectura detenida del texto arroja incertidumbres respecto de la magnitud de su aportación. Especialmente el análisis de su contenido permite concluir que el nuevo modelo de gestión del clima no se ajusta como debiera a lo que parece conveniente en el caso de un bien público global. La sustitución del esquema top down por el de bottom up no acerca al esquema hacia un modelo multilateral sino hacia otro multipolar, a través de la individualización del mecanismo de atribución de las obligaciones de reducción de emisiones. La consecuencia es que nos encontramos tan sometidos como antes, o incluso más, a la voluntad política de los Estados. Deberán ser estos los que, sin excesivas presiones al respecto en el nuevo Acuerdo, establezcan compromisos lo suficientemente ambiciosos para que el esfuerzo agregado permita pensar en una reacción efectiva al calentamiento global. Y eso no parece suficiente, en especial dado el ritmo de agravamiento de un problema que nos amenaza a todos.

Palabras clave: cambio climático, Convención Marco de las Naciones Unidas, Protocolo de Kyoto, Acuerdo de París, multilateralismo, multipolaridad.

\section{ABSTRACT \\ THE PARIS AGREEMENT OF DECEMBER 2015: THE REPLACEMENT OF MULTILATERALISM BY MULTIPOLARITY IN INTERNATIONAL CLIMATE COOPERATION}

The Paris Agreement breaks the perverse dynamic of international climate cooperation after the failed attempts in Copenhagen and Doha. This circumstance is the only one 
that justifies the enthusiasm with which it was received. However, the careful analysis of the text brings uncertainties regarding the magnitude of its contribution. Especially the analysis of its content allows to conclude that the new model of climate management does not fit as it should to what seems appropriate in the case of a global public good. The substitution of the top down for the bottom up approach does not bring the schema closer to a multilateral model but to a multipolar one, through the individualization of the mechanism for the attribution of emission reduction obligations. The consequence is that we are as subject as before, or even more, to the political will of the States. These should be those that, without a strong pressure on the issue in the new agreement, make commitments ambitious enough for the aggregate effort to think of an effective response to global warming. And this does not seem to be enough, given the pace of aggravation of a problem that threatens us all.

Keywords: Climate Change, United Nations Framework Convention on Climate Change, Kyoto Protocol, Paris Agreement, multilateralism, multipolarity. 